\title{
Hermeneutics of technological culture
}

\author{
Arun Kumar Tripathi ${ }^{1}$
}

Published online: 18 April 2017

(c) Springer-Verlag London 2017

\begin{abstract}
"All new technologies develop within the background of a tacit understanding of human nature and human work. The use of technology in turn leads to fundamental changes in what we do, and ultimately in turn what it is to be human. We encounter the deep questions of design when we recognize that in designing tools we are designing ways of being." (Preface: xi) Understanding Computers and Cognition. A New Foundation for Design by Terry Winograd and Fernando Flores.
\end{abstract}

\section{Is technology a cultural force?}

Our society is a technological culture. ${ }^{1}$ In the philosophy of technological culture, cultural analysis of technology is needed to be explored. Technology matters "because it is separable from being human" (Irwin 2016; Nye 2006; Bijker 2006). Borgmann (2006) suggests that for a proper understanding of our cultural malaise we have to get a grip on technology as a cultural force (See Borgmann 2008, 2010). We need a hermeneutic perspective, material hermeneutics, to analyze technological cultures. Our cultural lifeworld is technologically textured. Friis (2015: 215) describes "Technologies have become extended sense organs, enabling perception of realities never before known to us."A material hermeneutics can be best explored with human embodiment.

Arun Kumar Tripathi

tirelessarun@gmail.com

1 Central University of Tibetan Studies,

Sarnath, Varanasi 221007, Uttar Pradesh, India
It has become familiar today for us to blame technology for the various ills afflicting society. We rely on what we make to survive and live together in societies. Technological devices shape our rural societies, urban culture and the environment. They modify patterns of human activity. They influence who we are and how we live. Sometimes technological gadgets add to the excellence of our life style, and sometimes, they made our lives miserable. They engulf us, and we seem to be at a loss as to how to control them. Technologies such as automobiles, telephones and specs not only enlarge and extend our capacities, but also transform our experiences, thereby affecting changes in the natural and social worlds. In general, technologies either magnify or amplify our experiences, and can change the ways we live. This non-neutral, transformative power of humans enhanced by technologies is essential feature of the human-technology relations needed to be explored. The technological form of life is part and parcel of culture, just as culture in the human sense inescapably implies technologies. Technology can thus be seen as shaping the theoretical framework of our social existence.

Technology as the fundamental cultural force ${ }^{2}$ depends of course on one's definition. But even in the deep and wide sense, technology does not generate a totally new reality, but impresses itself as a pattern on all there is in various degrees (see Borgmann in this volume). And importantly, since it does so with our assent or complicity, this could

\footnotetext{
${ }^{1}$ Our existence is technologically textured (Ihde 1990: 2). Bijker (2001) argues that because "we live in a technological culture," we have an obligation to try to understand (that) "technological culture" (p. 19).

${ }^{2}$ I am thankful to Professor Albert Borgmann (Philosophy, The University of Montana, USA) for an e-mail dialogue on the topic of Technology as a cultural force and about the intricacies of technological culture in March 2016.
} 
and should give us ability to change the force of technology. However, if in a culture everything is technologically equipped (following technologically imperative), then most of the times one cannot avoid the use of technology. In a culture, where the use of technology is mandatory, has also an adverse effect on human beings. Borgmann (2006) tells us that there are the harms that come from the inducements that are built into the culture of technology, and people differ in their susceptibility to those inducements, and so does the severity of harms, e.g., obesity and distraction (see Borgmann in this volume). Gill (2010: 1) acknowledges Borgmann's plea that the "crisis of contemporary culture and the way the strategic conjunction of the market and technology is shaping institutional and governance culture, and how the modern technology as an engine of mechanization and commodification is seen as a temple of the expansion of affluence, happiness and vitality of contemporary culture."

Contemporary technologies either implicitly or explicitly relate to human perception, and they also point to the 'whole body' style of perceiving which we experience. Complex technologies teach us new things about our perception and the relation to the world. This phenomenological underpinning of technology has an impact on the cultural environment of technological development. My approach in the "Philosophy of Technological Culture" is inspired by Bernhard Irrgang's 'material hermeneutics' (Irrgang 2007, 2009, 2014; Tripathi 2016b) and Don Ihde's 'postphenomenology' (Ihde 1993, 2009a). Both approaches do not allow for a new answer to the classical questions in philosophy of technology formulated by Karl Jaspers and Martin Heidegger, who were concerned that technology would alienate us from ourselves and the world around us. Against this excessively abstract view; Verbeek (2005a) extends the work of Don Ihde, Bruno Latour, and Albert Borgmann to present an empirically rich and nuanced image of how material artifacts and technological devices shape our existence and experiences. A new interpretation of phenomenology offers possibilities par excellence for formulating a philosophy of technology from the perspective of things (Verbeek 2005a, b). Hasse (2008) tells us "Artifacts are multistable as cultural perceptions because learning organizes cultural knowledge about what is to be expected in the perceived world" (p. 51). Hasse (2013: 79-100) argues for a "multistable understanding of tools as signs, building on a combination of postphenomenology and cultural-historical activity theory to capture the embodied, cultural and historical learning processes initiated when technologies engage with humans in professional work life." Artifacts can only be "understood in terms of the relation that human beings have to them" (Verbeek 2005b: 117). Borgmann (2012a) informs us, the culture of technology is so powerful in its effect on our lives because its benefits seem so plausible. However, the actual broad effects of new technological devices, Borgmann says often defy and disappoint our expectations. By the culture of technology, Borgmann (2012a) means the "ensemble of technological structures (industries, utilities, businesses, etc.) and devices (cars, toasters, computers, etc.) and the effects that this ensemble has had on the quality of our lives." Borgmann tells us about the intricacies of technological culture in the developed world: "The indispensable common structure in the culture of technology is the system of utilities, the transportation links, the electrical grid, the Internet, the water supply, and more. No one in the industrial countries could survive for long without some support of that structure. Most of us, moreover, are tied to that structure through work" (Borgmann 2012b). However, the crucial trait of technology thought of as the form of our culture, is the detachment of things and practices from contexts of engagements with a time, a place, and a community (Borgmann 2012a).

Stapleton and Dowd-Smyth (2003) illustrate the "notion of techno-culture, emphasizing the non-neutrality of technology in the world and how technology can be used in cultural and economic colonialisation by the west." They inform us, philosophers and researchers recognize that technology, in particular information technologies, telecommunications and televisual technologies, are cultural artifacts. As such they are non-passive and not culturally neutral. Instead they embody the culture from which they were derived, and consequently, some have called the transfer of technology across cultural barriers as the transfer of "techno-culture" (Ihde 1998: 48).

On the question of how to analyze the phenomenon of technological mediation, Verbeek radicalizes Don Ihde's phenomenological approach of technology and offers a valuable framework in his work. In their analysis, Ihde and Verbeek understand technological mediation as the role technology plays in the relation between human beings and their world. Verbeek writes that "Ihde discerns several relationships human beings can have with technological artifacts." I concur with Ihde and Verbeek that technologies can be 'embodied' by their users, making it possible that a relationship comes about between humans and their world, and also technological artifacts are 'incorporated' as they become extensions of the human body (Verbeek 2005a, 2007, 2008). Technologies make possible new modes of access to reality that would be impossible without mediation. Technologies thus constitute a new reality, a new "objectivity" (Verbeek 2005a: 135). In fact, "Don Ihde's approach offers an alternative to the way the classical philosophy of technology has formulated the relation between technology and culture" (Verbeek 2005a: 135). Technological cultures do not solve our problems; they also produce the problem e.g. ethical problems. 
There is a multistable nature of culture and technology. "The interdependence of culture and technology is as old as human kind and civilization. Both culture and technology are embedded in an environment, which is transformed by the human person and also transforms the person" (McCarthy 1996: 144; Gill 1996b). "Social nuances, cultural values, and characteristics of traditional society are not generally taken into consideration in the pursuit of developing new technologies for social interaction" (Huang and Deng 2008: 81). Huang and Deng (2008) argue that social activities are inherently embodied in a cultural context. Culture manifests itself in cultural models, which are acquired through interaction with the environment (Huang and Deng 2008: 83). Sato and Chen (2008: 1) elaborates "Different cultures therefore produce different artifacts and environments based on their cultural characteristics. On the other hand, artifacts, through people's interactions with artifacts, influence cultures and can even produce a new culture." "Different cultures also interact with each other and produce intricate patterns of human behavior in relation to given situations". "Such cultural characteristics of users play a major role in their interactions with artifacts" explains (Sato and Chen 2008: 1).

In his paper "Technology as Cultural Instrument" (Ihde 1993: 32-42), Don Ihde argues to the effect that technology, as phenomenologically understood, is an essential expression of socio-historically situated human nature. It is basically cultural articulation of man and not an external adjunct. "Materiality of technological culture does not negate its cultural or human underpinnings. Therefore, wherever some form of technology, agricultural or metallurgical, is transferred by way of import or export, it carries with it a whole set of human relationships. It does not move in isolation and through social vacuum. When technology is negatively described as non-neutral its positive counterpart is obliquely hinted as its concrete and relationally ensembled character. When a cultural group migrates from one area to another, it takes with it not only its technology but its whole lifeworld, language, mode of perception, food habits, art form and other forms of value. Technology moves inseparably with people who experience and use it. It is environed by a gestalt-type cultural milieu. So transfer of technology is to be understood as a sort of intercultural encounter and gradual accommodation, not confrontation." Difference of culture promotes and provides for mutual learning and not necessarily entailing clash and conflict (Chattopadhyaya et al. 1992: 351-352).

Langdon Winner $(1980,1990)$ argues that "technology not only establishes specific social roles and relations, but also has a more general influence on everyday "forms of life." Technology also affects our everyday behavior, norms and values, our self-understanding and our perception with the world" (Smits 2001: 149). According to Winner
(1989) "philosophers of technology play an important role in fostering a moral sensibility in the modern technological culture." In pursuing the debate on technology and society, Gill (2015) says, "we may observe how seeing technological worlds as cultural visions enables us to reflect on the paradoxical process of viewing technology as part of a hope for a more sustainable and human-centered future, and as an instrument of surveillance, violence and catastrophes" (p. 139).

Ihde (2009a: 465) claims that "what makes technologies valuable for human practices are the non-neutral transformational capacities of these technologies. It is the subtle and profound transformation of experience." Our capacities for listening are changed by technological culture (Ihde 2007: 4). "It is not merely that the world has suddenly become noisier, or that we can hear farther, or even that sound is somehow demandingly pervasive in a technological culture" (Ihde 2007: 5). Ihde (2007) illustrates "it is rather that by living with electronic instruments our experience of listening itself is being transformed, and included in this transformation are the ideas we have about the world and ourselves" (p. 5). In our technological culture, the scientific view of knowledge dominates in the area of skill and knowledge transfer (Gill 1996a: 25). A technological culture increasingly seems to view the world not only in "mechanistic" terms but humankind as "like" a machine, even if the latest variant is that of a highly complex and programmed computer, says (Ihde 2007: 41).

Culture significantly contributes to creating the context, within which people understand their worlds, live and make decisions of ethical significance illustrates (Chattopadhyay and Simon 2008: 165). Technology enables the culture to explore other communication modes and expressions (Gill 1999: 220). "Culture is identity, because it is culture that ultimately enables human beings to exist and carry the meanings that allow them to exist and carry the meanings that allow them to know who and what they are", argues (Gill 1999: 221-222). Verbeek (2001: 133) describes "a culture is only what it is in the praxes in which it manifests itself-praxes that are mediated technologies." "Interweaving of technology and culture is an important phenomenon, where human beings use the technology. Technologies are always technologies-in-use." The "use context" is part of a larger cultural context. This contextuality describes by Ihde, makes technologies multistable, "in a way that is analogous to the different possible ways "seeing" the Necker cube: the same artifact can have different meanings or identities in different cultural contexts" (Verbeek 2001: 134). Don Ihde illustrates this multistability with the aid of examples involving technology transfer between cultures. 
Ihde uses the paradigm of cultural diversity and cultural diversification in his Philosophy of Technology. ${ }^{3}$

\section{Postphenomenology in the philosophy of technological culture}

Postphenomenology is an investigation of the relationships between global culture and technology (See Rosenberger this volume; Tripathi 2015). "Postphenomenology preserves the very structure of science and technology as multistable whereas claims for objective hermeneutics depend on the physical situatedness of the body" (Hasse 2008: 57). In a postphenomenological perspective, objects become multistable and new questions can be asked in line with the problematization of representationalism, argues (Hasse 2008: 57).

Postphenomenology takes on a concentrated focus upon human-technology relations. But it does so with rigorous scrutiny of particular technologies, rather than technology-in-general as in the earlier twentieth century thinkers, including Heidegger. Yet, once philosophy of technology reached its late twentieth century state, it had become obvious that praxis oriented philosophies were better suited than analytic approaches to detailing the effects of technological transformation (Ihde 2009a; Rosenberger 2015; Tripathi 2016a: 238).

By exploring postphenomenology, Ihde (2009a) addresses the cultural role of technologies in relations to perception, multiculturalism, and technoscience, and gives special consideration to the impact of image technologies, such as television and cinema, upon the contemporary world. However, postphenomenological mediation should also consider the issues of "cultural variability." Postphenomenologists must address the meaning of "socio-cultural activity." In addition, postphenomenologists should mull over whether embodiment itself has cultural \& historical variations.

Further, Ihde (2012b) rejects the entire Cartesian tradition, and instead opts for situated knowledge, but with an inter-relational ontology (ibid. p. 370). As can be seen, in each set of human-technology relations, the model is that of an inter-relational ontology (Ihde 2009a). "This style of ontology carries with it a number of implications, including ones which imply that there is a co-constitution of, for example, humans and their technologies. Technologies transform our experience of the world and our perceptions

\footnotetext{
3 Ihde's postphenomenology opens a new paradigm to study and compare different cultures. Ihde's philosophy of technology and material hermeneutics implicitly and also explicitly talk about Islamic and Indian cultures (Ihde 2009a).
}

and interpretations of our world, and we, in turn, become transformed in this process. Transformations are non-neutral. And it is here that histories and any empirical turn become effectively ontologically important. This, in turn, returns us to the pragmatist insight that histories are also important in any philosophical analysis as such" (Ihde 2009b). Ihde (2012b) shows that postphenomenology attempts to move farther from early modern epistemology by, as it were, substituting embodiment for subjectivity.

By elaborating Ihde's stand on postphenomenology (Tripathi 2016a: 238) tells us about "the importance of phenomenology in postmodern era, which diverges from classical phenomenology, such as in its focus on technological mediation, its reliance on "case studies" more familiar to the field of science studies and its kinship with many of the ontological commitments of American pragmatism."

In his book "Husserl's Missing Technologies" (Fordham University Press, 2016), Ihde (in his analysis of Husserl) ventures through the recent history of technologies of science, reading and writing, and science praxis, calling for modifications to phenomenology by converging it with pragmatism. This fruitful hybridization emphasizes human-technology interrelationships, the role of skilled embodiment, and the inherent multistability of technologies. In this perspective, technologies do have a powerful cultural variant, and it is thus important to study the "cultural variability" of postphenomenological mediation of technologies. It is also imperative to understand the vulnerability between technology and culture (Hommels et al. 2014). I have elsewhere (Tripathi 2008) described that the phenomenological experience in human-technology relations is to discover various structural features of human vision in the technologically mediated lifeworld, which is centered upon the ways we are bodily engaged with technologies in the concrete praxis.

Borgmann says, technology is not only a tool, it is an inducement, and it is so strong that for the most part people find themselves unable to refuse it. To proclaim it to be a neutral tool flies in the face of how people behave. However, tools are means of controlling and steering the interconnections between things and a device for co-ordinating shared human activities (Miettinen 2006). Cultural commodification can be defined as the detachment of a thing or a practice from its context of engagement with a time, a place, and a community (Borgmann 2006).

Technology is an activity that is intrinsic to humans is a claim made by many philosophers. It is important to explore what it means for humans to be technological beings. The issue of control over technology versus being controlled by technology remained an imperative one throughout the development of the philosophy of technology (Vries 2005). "When technology is introduced, both the human experiencer and the thing experienced are 
transformed. At this interrelational level, technologies may be more than just another object in the world of which the human experiencer is conscious - a point with which Husserl perhaps would have agreed", argues (Kelly 2015: 508).

In recent decades, the philosophy of technology has devoted much attention to an analysis of the relationships between humans and technologies. Technologies co-shape people's macroperception in many different ways. Verbeek (2011) argues that communication and transportation technologies, for instance, have made possible a cultural exchange on a large scale. This has resulted in a 'pluriculture', in which several frames of interpretation are needed simultaneously to understand it and live in it. "In our technological culture, scientific knowledge is not the sole property of scientists, but is increasingly forming the context against which humans understand themselves and the world around them" comments (Verbeek 2011). How technology, mediated by the different relationships that people can have with it, plays a vital role in the establishment of interpretative frameworks, scientific knowledge, and cultural practice!

At this point, Winner (1990: 59) asks: Can we imagine technologies that enhance democratic participation and social equality? "Engineers and technical professionals are the unacknowledged legislators of our technological age" argues (ibid. p. 59). Examining technologies solely on the basis of risk and benefit ignores the larger moral and political dimensions, and there is a danger of our society's unquestioning faith in technology by examining the concept of "risk" says Winner (1980). Winner (1989) suggests that when technology is being designed, the possible social effects of it should be looked at ahead of time, so they can be considered and worked on in the design of the technology. Also, Coeckelbergh (2016: 2) argues it is the "responsibility of the designers and users of technology to develop and use technology in a responsible way." Winner (1990) is suggesting that all parties that will be affected by the technology, such as workers using a technology, be a part of the design.

\section{Cultural visions of technology}

Technology becomes subordinate to values through economics, government, or the professions. "Our biggest problem is learning to recognize that we do have options, albeit often limited ones. Our tendency is to just create more technology rather than ask why", argues (Mitcham 2001).

Rasmussen (2013) paper "Cultural visions of technology: Paradoxes of panoptic and interactive perspectives and methods" is perfect to elaborate the prospects of the theme of this special volume of the Journal. "The increasing influence of technology in modern societies has been seen by some as offering great promise for the future, but by others as creating the electronic surveillance and/or manipulation of human genes, minds and beliefs." Rasmussen (2013: 177) argues for considering technological worlds as cultural visions to discuss and reflect the paradoxical process of viewing technology as part of a hope for a more sustainable and human-centered future as well as part of an apocalypse of surveillance, violence and catastrophes (See also Rasmussen 1996).

Rasmussen (2013) reflects that "the interactive vision of human-centered technology refers to two aspects of human creativity. First, shaping of technology is a fundamental expression of human life activity. This ability has crystallized into the evolutionary process that has allowed mankind to enter a social/historical process. Second, participation in the shaping of technology includes the capacity for understanding one's own societal conditions as well as active participation in the shaping of these conditions" (p. 180). "By insisting that technology-culture structures are multistable, Ihde allows a certain degree of relations in his cultural hermeneutics" (Ihde and Selinger 2003, p. 218). All technologies display ambiguous, multistable possibilities (Ihde 2002: 106). Since 1990, Don Ihde has been pleading that philosophers usually expected to play the role of applied ethics often come to the scene after these effects are known. But others who participate at the research and development stages find even more difficulties with prognosis, argues Ihde (1999).

Irrgang (2007) argues that technical culture includes technology ideals, technology images, technical philosophies and ideologies. These are not always based on ethical principles, but nevertheless with different assessments of techniques are (almost) constitutive for technology interpretations. Technology leads to social differentiation. Technical forms of life influence society and of course also the way people live and work. The design of technology itself is now a question of power. It is born from two aspects, namely the competence of dealing with technical artifacts and as a dispositive of technical structures itself. Postphenomenological philosophy of technology does not support the alienation theory of critical theory of technology. For this reason, the postphenomenological perspective is a completely different view of the world than other interpretation approaches. It allows a more differentiated, an empirically oriented view for the exploration of specific technologies. The postphenomenology allows technologies to not only describe in terms of their functionality, but also as an operator with regard to the relationship between people and their world (Irrgang 2014).

Tools change the range and the direction of human development, yet there must remain some goal outside of technology which machines should help us to reach (Rothenberg1993: xiii). Verbeek (2005a) describes what Ihde in 
fact brings to light is that technologies can create a "technologically mediated" intentionality, a relationship between humans and a world in which their mutual constitution is mediated by technological artifacts (p. 140). According to Verbeek (2005a) "technology mediated intentionality" is a "relation between human beings and world mediated by a by technological artifact" (p. 116). With 'technological intentionality', Ihde indicates that technology has "intentions"- they actively shape people's relations with their world (Ihde 1990: 141-143). "When technologies are used, they co-shape human-world relationships: they make possible practices and experiences, and in so doing, they play an active role in the way humans can be present in their world and vice versa" (Verbeek 2005b: 140). Verbeek defines "technological intentionality", as an abbreviation of "technologically mediated intentionality" (ibid. p. 140).

Postphenomenology does not abolish the distinction between humans and nonhumans, but shows their fundamental connectedness and interrelatedness. "Artifacts mediate ways of existence (subjectivities) and experienced realities (objectivities) not because people told them to do so, but because of the relation between humans and the world that comes about through them" (Verbeek 2005b: 140). "Contemporary philosophy of technology emphasizes this "use" aspect of technologies: what matters for understanding and evaluating technologies is not only the material artifact and its immediate and intended function, but also its unintended effects as it is and becomes part of a social and natural environment. Use varies according to who uses it, but also more generally it varies according to the social context", explains (Coeckelbergh 2015).

Thus, Coeckelbergh (2015) argues "technology is not simply a matter of "artifacts" or "things", but shapes how we see reality (it shapes our world) and what technology "is" depends on how it is used in various contexts argues Inspired by the phenomenology of perception", as Ihde (1990) explains this variety in meaning the "multistability' of technologies: they do not have meaning apart from the contexts and cultures in which they are used; there are technology-culture structures and hence there is diversity and ambiguity in technology, comments (Coeckelbergh 2015; See also; Ihde 1999, 2002). It is argued (Coeckelbergh 2015) that "vulnerability coping is a matter of ethics and art: it requires developing a kind of art and techne in the sense that it always involves technologies and specific styles of experiencing and dealing with vulnerability, which depend on social and cultural context."

However, as technologies get more complex, it is more difficult to see in what sense they are extensions of our human organs. Let us take the Internet as an example. In a way this can be seen as an extension of our human voice, because it replaces us telling the information to each other.
But the system is very complex and contains several elements that are not directly extensions of the human voice and its effects are much more than just extending the amount of shared information over larger (Vries 2005). So Ernst Kapp's analysis is too simplistic to serve as an adequate description of what the Internet is. Kapp would see the mobile phone as an extension of the human body. Kapp's theory of extension of human body seems quite plausible. But as technologies get more multifaceted, it is more difficult to see in what sense they are extensions of our human bodies. Instruments tell the inadequacies of human body (Ihde 2004a; Verbeek 2015; Tripathi 2016a). Steinert (2016) also came to conclusion that "the idea of a projection of organs into external means is an intuitive account of how a limited set of simple tools might have developed as a replication of the morphology and functions of some organs, it does not fare well when it comes to complex technical artifacts." (Rothenberg 1993, p. 14) in addition argues "if we understand the application of a tool appropriately, the more ways we conceive of how it may be put into practice. Our desires and intentions to act upon the world are themselves changed through the tools that we realize them. This is the epitome of the philosophy of technology as human extension."

Don Ihde (1990) introduced the idea of multistability into the philosophy of technology in technology and the lifeworld (Notion of multistability is extended in Ihde (2012c)). The idea is that, like a Necker cube illusion, which can be interpretatively seen with either the top right or bottom left corner as the frontmost surface, the path that a technology will take both in its development in the way that it suggests interpretive possibilities for economic and political application is neither wholly flexible nor wholly determined (Tripathi 2014).

On one hand, I argue technologies are culturally multistable, and on the other hand perception as a hermeneutical act. My notion of multistability of human perception is based on the fact that I can interpret the perception (which I call as a hermeneutical act) in different ways, to cope with realities in a culture. There must be more than one way of interpreting the perception, so is also the multistable hermeneutics relations with technologies. There must be different ways to interpret the technologies where technologies are culturally embedded. My notion of multistable hermeneutics relations with technologies is open to interpret the technologies in different ways. One technology can be seen different in different cultures, based on its usage, through technologies, a culture is interpreted. In a sense, Irrgang's notion of multiperspectivity can be more useful than Ihde's notion of multistablity in the philosophy of technologies or both can be combined to seek out the main 
task of technology reflection culture. " The multistability of cultural relations to the world implies not only that artifacts can have different meanings in different cultural contexts, but also that the same goals can be technologically realized in different ways. The favorite example as given by Don Ihde is; western navigational techniques and the traditional navigational techniques of the South Sea islanders. Western navigation is strongly instrumentally mediated and mathematical in nature. Whereas South Sea islanders navigate by carefully observing stationary clouds' birds, and wave patterns", explains (Verbeek 2001: 135).

(Verbeek 2005a: 137) further elaborates "Human ends can be realized in many different ways, depending on the cultural context in which they play a role. Different cultural contexts (different 'ways of seeing'), thus can lead to the development of different technologies." So questions can be asked: Is the cultural relation to technologies multistable, or do technologies have a culture-changing power? Perceptions are mediated by technologies argues (Verbeek 2001: 138). Technologies do not exist 'in themselves', but only as related to humans and to culture. Technology always exists in its cultural contexts. Technology always only function in concrete, and practical contexts (Ihde 1990; Verbeek 2005a, b). On the intricacies of technological mediation, Friis (2012: 365) correctly argues that "trained judgment of perceptual experiences-bodily perceptual skills acquired through development of expertise-have a tremendous impact on our ability to understand what technologies in fact are mediating."

Technologies do have adverse societal consequences: "Technology has positive impact only when amplifying social trends or institutions that are already positively inclined." "...the explosion of misinformation surely counts as a negative consequence of technology. Frictionless sharing is technology, but to what end?" This is the crux of the argument of Vardi (2017). Don Ihde argues perceptions are bodily activities, not the actions of some homunculus inside a camera obscura box looking at mental images which represent something 'out there.' In phenomenology, variations are the means by which possibility structures are discovered. Phenomena may undergo variations, reversibilities and multiple possibilities (Ihde 2004b).

\section{Reflections: philosophy of technological culture}

This special volume on Philosophy of Technological Culture explores questions such as what is to be human in the

\footnotetext{
4 Thanks to Professor Jan Kyrre Berg Olsen Friis (University of Copehagen), July 2015 for an e-mail dialogue on Cultural Multiperspectivity: Irrgang's multiperspectivity would be interesting to extend \& develop postphenomenology, conceptually and thematically, and perhaps methodically as well.
}

era of technological culture? How human actions and perceptions influence a technological culture? How a culture is being influenced by technological developments and vice versa? How will new artifacts or technologies impact our culture and vice versa? How do different cultures interact during human-artifact interaction?

Technology often looks like it is autonomous and rampaging around the world. But is there a sense in which technology is driven and controlled by economic interest? How do we make sure that human values are in the driver's seat when technology decisions are made? (see Mitcham's interview on Philosophizing About Technology: Why Should We Bother? in 2001). As soon as we start to use technological devices and gadgets, our body changes speed, conduit and uniformity. New technological assemblages change our way of acting in and transforms our world. How do we understand the transformation made by technological devices, gadgets and apparatuses we are using?

The question of the contemporary relevance of Heidegger's reflections on technology to today's advanced technology is explored in Babette Babich's paper on "Heidegger on technology and Gelassenheit: wabi-sabi and the art of Verfallenheit" with reference to the notion of "entanglement" towards a review of Heidegger's understanding of technology and media and modern digital life by Babette Babich. Heidegger's reflections on Gelassenheit have been connected with the esthetics of the tea ceremony, disputing the material esthetics of porcelain versus plastic. After all, Babich argues, philosophers of technology, like philosophers of science, ought to know their subject matter-and how much technology could there have been in the years before, during, and after the two wars, i.e., years that span Heidegger's Being and Time, his reflections on "The Age of World Picture", and all the way to the postwar Bremen and Munich lectures that became The Question Concerning Technology? Given such modest non-modern technologies, Babich asks "what could Heidegger know of the modern world in which we today text and tweet, a world of the new future in which we travel by plane and rail and automobile?"

In his paper on "Explanation in philosophy and the limits of precision", Rebecca Bendick and Albert Borgmann argue that "Anglo-American philosophy show that precision of presentation is a commendable and widely pursued goal. There is a trade-off, however, between precision and richness of presentation." As precision gets sharpened, impoverishment of subject matter advances, often without recognition of the price that is paid for precision. A precise way of illustrating the trade-off in question is to take a precise meteorological model, consider how little it tells us about the weather, enrich the model, and see how precision loses its edge. They have mentioned the works of 
Heidegger and Rawls as exemplars of balance between precision and richness.

In their paper, authors want to show that computational modeling gives us a clear picture of the limits of precision in explanation-there is always a trade-off between the precision of explanation and the richness of the phenomena that are captured in an explanation. In American mainstream philosophy, often called analytic philosophy, these limits are frequently concealed, and that concealment leads to the unwitting impoverishment of philosophy in the pursuit of precision.

Mark Coeckelbergh's paper on "Language and technology: maps, bridges, and pathways" argues that contemporary philosophy of technology after the empirical turn has surprisingly little to say on the relation between language and technology. Coeckelbergh's essay describes this gap, offers a preliminary discussion of how language and technology may be related to show that there is a rich conceptual space to be gained, and begins to explore some ways in which the gap could be bridged by starting from within specific philosophical subfields and traditions. One route starts from the philosophy of language (both "analytic" and "continental": Searle and Heidegger) and discusses some potential implications for thinking about technology; another starts from artifact-oriented approaches in philosophy of technology and STS and shows that these approaches might helpfully be extended by theorizing relationships between language and technological artifacts. Coeckelbergh's essay concludes by suggesting a research agenda, which invites more work on the relation between language and technology. ${ }^{5}$

Coeckelbergh says, if philosophy of technology needs to engage with philosophy of language, therefore, it should be clear that there are roughly two options in relation to which it must position itself: either an analytic approach which usually assumes that language is an external object and instrument, or a Heideggerian approach which sees language as what Kusch has called a "universal medium" as opposed to language as "calculus" (See Coeckelbegh this volume). Coeckelbergh makes the plea that "contemporary philosophy of technology has done much to "bring together" humans and machines (cyborg metaphor ${ }^{6}$ ), humans and things. There is also a lot of other interesting thinking through technology (to use an expression by Mitcham, See Mitcham 1994, 2001)." But we also need to realize that this is also always thinking through words, says Coeckelbergh.

\footnotetext{
${ }^{6}$ Some of the topics (cultural-historical phenomenon) are discussed in Coeckelbergh (2017a).

${ }^{5}$ In his forthcoming book, Coeckelbergh (2017b) offers a systematic argument for interweaving thinking about technology with thinking about language.
}

Siby George's essay "Total enframing: Global South and techno-developmental orthodox" articulates about Heidegger in the context of Global South and sketches Heidegger's philosophy of technology in the Indian perspectives. Siby George argues that Martin Heidegger describes technology in essence as the late modern Western understanding of Being which is planetary in its reach. Succeeding the long phase of colonialism after World War II, the history of the global spread of this understanding of Being is intertwined with the developmental and globalization eras in the Global South. Techno-capitalist development crowds out alternative forms of economic and social life, which have been meaningfully prevalent in the Global South. Moreover, the monistic metaphysics that powers developmentalism makes alternatives impossible. However, alternative political possibilities still exist, which are postmetaphysical and post-techno-developmental.

Taking the Heideggerian critical ontology of technology as its base, Siby George looks at postcolonial modernization and development in the global south as the worldwide expansion of the western metaphysical understanding of reality.

Steffen Steinert's paper on "Technology is a laughing matter: Bergson, the comic and technology" laments that there seems to be no connection between philosophy of humor and the philosophy of technology. Steinert pursues a twofold goal in this paper: First, he takes an account from one of the seminal figures in the philosophy of humor, Henri Bergson, and brings out its merits for a philosophy of technology. Bergson has never been fully appreciated as a philosopher of technology. However, in the end Steinert fill this gap and shows that Bergson's account of the comic contains some interesting insights about our relation to technology. Second, Steinert demonstrates that humor and the comic open up a new perspective on technology that may facilitate new ways of thinking about our technological culture.

Danish phenomenologist and hermeneut Jan Kyrre Berg Olsen Friis's paper on "Gestalt descriptions embodiments and medical image interpretation" argues that medical specialists interpret and diagnose through technological mediations like X-ray and fMRI images, and by actualizing embodied skills tacitly they are determining the identity of objects in the perceptual field. Perception is a hermeneutical act. Friis comments "The initial phase of human interpretation of visual objects takes place during the moments of visual perception before we are consciously aware of the

\footnotetext{
${ }^{7}$ Siby George has expanded the hypothesis in the book "Heidegger and Development in the Global South, New Delhi: Springer India, 2015." George (2015) discusses the question: How do the people of the global south respond to technological modernity and the logos that powers it? George (2015) is setting the premise for a Heidegger's philosophy of technology in India.
} 
perceived. What facilitate this innate ability to interpret are experiences, learning and training that become humanly embodied skills." These embodied skills, Friis argues, are actualized during the moments of visual perception. Friis main argument is that biology, society, and instruments constitute unique individual ontologies influencing specialist readings of the technological output, in other words, putting limits on the "truth-to-nature" relation, which is so much sought for in science. Cultural skills account for the radiologist's developed skills necessary to interpret the specific images of his particular subspecialty. Other skills are innate, like seeing, tasting, smelling, etc., what we smell or what we touch feels like are skills we learn through our bodies, argues Friis.

In his paper on "Ethics of responsibilities distributions in a technological culture" Hans Lenk develops and differentiates some problems of the interaction between corporations, individuals and the general public as well as institutions like the state or international non-governmental organizations as well as super-national organizations. Lenk argues that in our culture, we have to deal with rather ramified types of individual and collective as well as specific corporate responsibilities tending to reach out beyond national borders, specific state law restrictions and even business systems and economies. The traditional personal and individual responsibility and their different forms will not do to cope with all the respective international, intercultural and inter-sectoral problems of modern corporations and their international interactions. Lenk discusses the question: Do multinational organizations and corporations have a sort of specific corporate responsibility, and if so, against whom and for what-except for their share- and stakeholders?

Hans Lenk recognizes that the distributions of ethics of responsibilities play a crucial role in enforcing a paradigm in the critical development of science and technology which seems to open a perspective for the philosophy of technology and culture.

Robert Rosenberg's paper "On the hermeneutics of everyday things: or, the philosophy of fire Hydrants" explores this question: How the material objects of our world shape our choices and abilities and interactions on one hand, but on the other are also designed and altered and used by us? He notes that sometimes it can be difficult to think about "everyday" objects, those things we are so familiar with that they become taken-for-granted aspects of the backdrop of our world. But what if those objects, despite their everydayness, are politically fraught and call for closer examination? Rosenberger is suggesting that insights from two contemporary perspectives, postphenomenology and actor-network theory are useful for drawing out the experiential, social, and political dynamics of everyday things. In this paper, Rosenberger reviews and resituates several key concepts from these two theoretical frameworks and outline a method for using them together for the evaluation of technology. As a guiding example, Rosenberger explores a paradigmatic everyday device: fire hydrants. Despite their everyday character, hydrants fulfill multiple social roles, some of them loaded with difficult and important political implications.

Rosenberger argues that two particular contemporary theories, postphenomenology and actor-network theory, when used together provide a particularly useful perspective for approaching these issues. More specifically, Rosenberger suggests that the postphenomenological conception of "multistability" (i.e., the understanding that a technology is always open to multiple uses and meanings) is especially important.

Mashelkar's paper on "Impact of science, technology and innovation on the economic and political power" provides his own perceptions on the way science, technology and innovation is going to determine the economic and political power of the nations. The rapid paradigm shifts that are taking place in the world as it moves from super power bipolarity to multipolarity, as industrial capitalism gives way to green capitalism and digital capitalism, as information technology creates netizens out of citizens, as aspirations of the poor get fueled by the increasingly easier access to information, as the nations move from 'independence' to 'interdependence,' as national boundaries become notional, and as the concept of global citizenship gets evolved, we will be full of new paradigms and new paradoxes, there is no doubt that the rapid advance of science and technology will directly fuel many of these.

Mashelkar puts forward a thesis "Technology is not always the offspring of science" which has an importance in the philosophy of technology tradition. Quite often, technology precedes science ${ }^{8}$. Steam engine came before the laws of thermodynamics were understood. A major part of new technologies indeed evolve from already existing science and technology. Many advances and innovations in technology are essentially incremental improvements in existing technologies. A technology can give rise to new technologies, the so-called 'spin-off' technologies. It is not only that new science gives rise to new technology, but the reverse is also true: new technology gives us new science. The interconnection of science, technology and innovation and its enforcement of paradigm seem to open a horizon for philosophy of technology and culture. The world 'boson' to describe elementary particles that obey the Bose-Einstein statistics is now a part of language and culture. The paper

\footnotetext{
${ }^{8}$ This is also discussed by Don Ihde in "The Historical-Ontological Priority of Technology over Science" (pp. 25-46) in Existential Technics, Don Ihde, SUNY Press, 1983. "For Heidegger, technology's ontological priority over science shows that all science must be, in my term, technoscience" (Ihde 2009a: 35).
} 
adds a cultural dimension to the development of science, technology and innovation.

Paul Durbin's paper "Brain research and the social self in a technological culture" notes that the social problems of our technological culture are numerous, and call out for the cooperation of everyone, of scientists and humanists, as well as of knowledgeable citizens, not to mention the socially responsible public figures. It is a daunting task. But collectively we can do that.

Durbin's main argument is to proceed in well defined stages: First and foremost he introduces the history of anti-reductionism among philosophers, including those of the analytical persuasion, especially among North American philosophers. He then introduces "new archaeology" of hominid prehistory to show how some eminent archeologists oppose the reductionist view that large brainsdeduced from finds of larger and larger skulls - constitute the best explanation we have for the advent of Homo sapiens. Durbin then introduces Berger and Luckmann's Social Construction of Reality to make a central claim: that even reductionist science-whether genetic reductionism or brain-studies-based reductionism-is and must be socially constructed; and in the end, Paul Durbin concludes with a preference for a Meadian (similar to a Deweyan) social responsibility activism.

Albert Borgmann's paper "The force of wilderness within the ubiquity of cyberspace" argues that Wilderness 9 and cyberspace are opposites and yet are poorly defined and set off against each other. Wilderness ${ }^{10}$, in fact, is enveloped by cyberspace and so seems to have become disposable and replaceable. The legal delimitation of wilderness requires us, however, to stop and consider how to cross over into it, and if entered thoughtfully, the wilderness can teach us to recognize how, within cyberspace, it has attained a new kind of sacred force. Wilderness engages us in the original human practices of walking, building, and dwelling, says Borgmann.

Manjari Chakrabarty's paper on "A philosophical study of human-artefact interaction" focuses on a critical intersection between philosophy of technology and cognitive archaeology. Chakrabarty argues, these two rapidly

\footnotetext{
${ }^{9}$ Bugbee (1974) elaborates "The pervasive culture seems to be in dialectical contrariety to a wilderness ethos. Technology may be the mechanical embodiment-the vehicle-of that culture, seemingly endowed with overwhelming autonomy. Yet the language of the culture betrays the underlying human stance" (617).

${ }^{10}$ Wilderness is a learning process. Wilderness is tangible, whereas Cyberspace is ethereal. Albert Borgmann gave a talk on "The Force of Wilderness within the Ubiquity of Cyberspace" (courtesy mcat. org) https://www.youtube.com/watch?v=WHHIXfZoqMk at the University of Montana Wilderness Institute in 2013 under the theme of "Wilderness on the Edge: The Emerging Roles of Wild Lands in Changing Landscapes."
}

developing disciplines intersect on the problem of characterizing the dynamic relationship between human beings and technical artifacts. It is also argued that the intricacies of human-artifact relation have been a source of curiosity and contemplation for philosophers of technology since 1970s. In contrast, the emphasis is on the cognitive archeologists' interest in interpreting the exact nature of the interaction between human cognitive system and material culture. The central idea of Chakrabarty's paper is to show why the cognitive archeologists' account of the relation between human cognition and material culture as exemplified by the classical phenomenological example of the blind person's use of a stick needs to be critically reviewed in the light of philosophical-(post)-phenomenological research and new empirical findings on tool use and prosthesis.

In conclusion, as hermeneutics philosophers of technology, Ihde, Irrgang, Rosenberger, Selinger, Verbeek explore the questions such as what role does technology play in everyday human experience? and how do technological artifacts affect people's existence and their relations with the world? The ways technological practices themselves structure actions include different forms of meaningfulness. The development of a philosophy of technology is, in principle, based on the assumption that substantial philosophical questions can be posed against the technology as proposed or in the view of the social implications arising out of new organizational, economical and technological developments such as globalization, economics, population growth, ecological crisis, north-south conflict, worldwide communication technology and information distribution. Thus, the relevant questions posed by a philosophy of technology are: "Have we access to the techniques or technologies that we need?" "Do we need the technology that we have?" The answers to these questions have a profound affect on human culture. Human culture has developed the ability to improve the functions of the human perceptual structure by incorporating new technologies into its cognitive functioning, to enlarge in this way to cope the reality. Philosophy of technology tells us that the social and cultural changes are neither determinate nor generally foreseeable; and because of this, the changes will demand special attention. The task for a philosophy of technology is to analyze the phenomenon of technology, and the ways it significantly mediates and transforms our experience and perception of the lifeworld (Kaplan 2004, 2008, 2011; Tripathi 2014; Irrgang 2014). The philosophers of technology "should reposition themselves" in the "R\&D" position where "technologies are taking developmental shape, in think tanks, in incubator facilities, in research centers. Only then can truly 'new' and emerging technologies be philosophically engaged" (Ihde 2012a: 332). The imaginary variations in postphenomenology talks about the bodily technology set of "cultural" relations and the phenomenological structure of human-world 
possibilities. Don Ihde suggests a bare sketch of a postphenomenological, engage, R\&D situated practice, which is simultaneously demanding and agreeable (Ihde 2003).

Acknowledgements I would like to sincerely thank authors of this special volume, Babette Babich, Paul Durbin, Jan Kyrre Berg Olsen Friis, Steffen Steinert, Raghunath Mashelkar, Albert Borgmann, Rebecca Bendick, Mark Coeckelbergh, Hans Lenk, Robert Rosenberger, Siby George and Manjari Chakrabarty for their incisive and reflective contributions as well as to several reviewers for their help and support. I am especially thankful to Dr. Larry Stapleton (INSYTE, Waterford Institute of Technology, Republic of Ireland) for his e-mail dialogue on HCS analysis which plays a vital role in the Philosophy of Technological Culture.

\section{References}

Bijker WE (2001) Understanding technological culture through a constructivist view of science, technology, and society (pp. 19-34). In: Cutcliffe SH, Mitcham C (eds) Visions of STS: counterpoints in science, technology, and society studies. SUNY Press, New York

Bijker WE (2006) The vulnerability of technological culture. Cultures of technology and the quest for innovation. In: Nowotny $\mathrm{H}$ (ed) Berghahn Books, New York, pp 52-69

Borgmann, A (2006) Technology as a cultural force in: for Alena and Griffin. Can J Sociol Cahiers Canadiens de sociologie 31(2):351-360

Borgmann A (2008) The growth of information and the texture of reality. Explor Media Ecol 7(4):241-254

Borgmann, A (2010) Orientation in technological space. First Monday, [S.1.], Jun. 2010. ISSN 13960466. doi:10.5210/ fm.v15i6.3037.http://journals.uic.edu/ojs/index.php/fm/article/ view/3037/2568. Accessed 14 Feb 2017

Borgmann A (2012a) The collision of plausibility with reality: lifting the veil of the ethical neutrality of technology. Educ Technol 52:40-43

Borgmann A (2012b) Matter matters: materiality in philosophy, physics, and technology materiality and organizing. In: Leonardi PM, Nardi BA, Kalinikos J (eds) Oxford University Press, Oxford, pp 335-347

Bugbee HG (1974) Wilderness in America. J Am Acad Relig 42(4):614-620

Chattopadhyay S, Simon A (2008) East meets West: cross-cultural perspective in end-of-life decision making from Indian and German viewpoints. Med Health Care Philos 11:165-174. doi:10.1007/s11019-007-9106-y

Chattopadhyaya, DP, Embree, LE, Mohanty, J (eds) (1992) Phenomenology and Indian Philosophy. SUNY Press, Albany

Coeckelbergh M (2015) The art of living with ICTs: the ethics-aesthetics of vulnerability coping and its implications for understanding and evaluating ICT cultures. Found Sci. doi:10.1007/ s10699-015-9436-9

Coeckelbergh M (2016) Technology and the good society: a polemical essay on social ontology, political principles, and responsibility for technology. Technol Soc (forthcoming) 1-6. doi: 10.1016/j.techsoc.2016.12.002

Coeckelbergh M (2017a) New romantic cyborgs: romanticism, information technology, and the end of the machine. MIT Press, Cambridge

Coeckelbergh M (2017b) Using words and things: language and philosophy of technology. Routledge, New York
Friis JKBO (2012) Perception: embodiment and beyond. Found Sci 17:363-367. doi:10.1007/s10699-011-9242-y

Friis JKBO (2015) Towards a hermeneutics of unveiling. In: Rosenberger R, Verbeek P-P (eds) Postphenomenological investigations: essays on human-technology relations (215-226). Lexington Books, Lanham, MD

George S (2015) Heidegger and development in the global south. Springer India, New Delhi

Gill KS (1996a) The foundations of human-centred systems (pp. 1-68). In: Gill KS (ed) Human machine symbiosis the foundations of human-centred systems design. Springer-Verlag London Limited, London

Gill, KS (1996b) EU Report "Knowledge Networking" Basis of the first EU-India Cross-Cultural Innovation Network project funded by the EU (1998-2003), directed by Prof. Gill. http://www. it.bton.ac.uk/research/seake/publication.html. http://www.it.bton. ac.uk/research/seake/knowledge.pdf

Gill SP (1999) Mediation and communication of information in the cultural interface. AI Soc 13:218-234

Gill KS (2010) Ethics of calculation. AI Soc 25:1-3. doi:10.1007/ s00146-010-0266-6

Gill KS (2015) Beyond systems: in search of poietic thinking AI \& Soc 30:139-141. doi:10.1007/s00146-014-0576-1

Hasse, C. (2008). Postphenomenology: learning cultural perception in science. Hum Stud 31(1):43-61. doi:10.1007/ s10746-007-9075-4

Hasse (2013) Artifacts that talk: mediating technologies as multistable signs and tools. Subjectivity 6:79-100 doi:10.1057/sub.2012.29

Hommels A, Mesman J, Bijker W (eds) (2014) Vulnerability in Technological Cultures: New Directions in Research and Governance. MIT, Cambridge, Massachusetts

Huang K, Deng, Y (2008) Social interaction design in cultural context: a case study of a traditional social activity. Int $\mathrm{J}$ Des [Online] 2:2. http://www.ijdesign.org/ojs/index.php/IJDesign/ article/view/341/168

Ihde D (1990) Technology and the lifeworld: from garden to Earth. Indiana University Press, Bloomington

Ihde D (1993) Technology as cultural instrument. In: Postphenomenology: essays in the postmodern context. Northwestern University Press, Illinois, pp 32-42

Ihde D (1998) Expanding hermeneutics: visualism in science. Northwestern University Press, Evanston

Ihde D (1999) Technology and prognostic predicaments. AI Soc 13:44-51

Ihde D (2002) Bodies in technology, (electronic mediations), vol 5. University of Minnesota Press, Minneapolis

Ihde D (2003) Postphenomenology-Again? (pp. 1-30) Working Papers from Centre for STS Studies Department of Information \& Media Studies, University of Aarhus, Published by The Centre for STS Studies, Aarhus

Ihde D (2004a) Philosophy of technology. In: Kemp P (ed) World and Worldhood / Monde et Mondaneite (Philosophical problems today), vol 3. Springer, Dordrecht, pp 91-108

Ihde D (2004b) The ultimate phenomenological reduction. Interfaces Image Text Lang 1(21/22):59-68

Ihde D (2007) Listening and voice: phenomenologies of sound, 2nd edn. SUNY Press, Albany

Ihde D (2009a) Postphenomenology and technoscience: the Peking University lectures. SUNY Press, New York

Ihde D (2009b) From da Vinci to CAD and beyond. Synthese 168:453-467. doi:10.1007/s11229-008-9445-0

Ihde D (2012a) Can continental philosophy deal with the new technologies? J Specul Philos 26(2):321-332

Ihde D (2012b) Cartesianism' Redux or Situated Knowledges. Found Sci 17:369-372. DOI:10.1007/s10699-011-9243-x 
Ihde D (2012c) Experimental phenomenology. Second Edition Multistabilities. SUNY Press, Albany

Ihde, D \& Selinger, E eds. (2003) Chasing Technoscience: Matrix for Materiality, Indiana University Press, 2003

Irrgang B (2007) Hermeneutische Ethik. Pragmatisch-ethische Orientierung in technologischen Gesellschaften [Hermeneutics ethics. Pragmatically ethical orientation in technological societies]. Wissenschaftliche Buchgesellschaft, Darmstadt

Irrgang B (2009) Grundriss der Technikphilosophie: Hermeneutisch phanomenologische Perspektiven [Philosophy of technology: Hermeneutics-phenomenological perspectives]. Wuerzburg. Koenighausen \& Neumann, Germany

Irrgang B (2014) Handling technical power: philosophy of technology (G. Somasekharan, trans.). Franz Steiner Verlag, Stuttgart

Irwin SO (2016) Digital media: human-technology connection. Lexington Books, Lanham

Kaplan D (2004) Readings in the philosophy of technology. Rowman \& Littlefield, Lanham

Kaplan D (2008) How to read technology critically. In: Olsen J, Selinger E, Riis S (eds) New waves in philosophy of technology. Blackwell Publishers, London, pp 83-99

Kaplan D (2011) Paul Ricoeur and the philosophy of technology. In: Erfani F (ed) Paul Ricoeur: honoring and continuing the work. Lexington Books, Lanham, MD, pp 21-33

Kelly MR (2015) Edmund Husserl In: Ethics, science, technology, and engineering: a global resource. In: Holbrook JB, Mitcham C (eds) MI: Macmillan Reference USA/Cengage Learning, Farmington hills 2nd edn, vol 4, pp 507-509

McCarthy E (1996) Culture, mind and technology: making a difference. In: Gill KS (ed) Human machine symbiosis: the foundations of human-centred systems design. Springer-Verlag London Limited, London. pp 143-176

Miettinen R (2006) Epistemology of transformative material activity: John Dewey's pragmatism and cultural-historical activity theory. J Theory Soc Behav 36(4):389-408

Mitcham C (1994) Thinking through technology: the path between engineering and philosophy. University of Chicago Press, Chicago

Mitcham C (2001) Philosophizing about technology: why should we bother? In: Ethix: business, technology, ethics. http://ethix. org/2001/06/01/philosophizing-about-technology-why-shouldwe-bother. Online Access 20 Mar 2017

Nye D (2006) Technology matters-question to live with, MIT Press, Cambridge, MA

Rasmussen LB (1996) Human-centred methods of social and technical design, pp 203-254. In: Gill KS (ed) Human machine symbiosis the foundations of human-centred systems design. SpringerVerlag London Limited, London

Rasmussen LB (2013) Cultural visions of technology: paradoxes of panoptic and interactive perspectives and methods. AI Soc 28:177-188. DOI:10.1007/s00146-012-0408-0

Rosenberger R (2015) "Postphenomenology What's New? What's Next?," Technoscience and postphenomenology The Manhattan Papers. In: Friis JKBO, Crease RE (eds) Lexington Books, Lanham, pp 129-148

Rothenberg D (1993) Hand's end: technology and the limits of nature. University of California Press, Berkeley

Sato K, Chen K (2008) Special issue editorial: cultural aspects of interaction design. Int J Des [Online] 2:2. http://www.ijdesign. org/ojs/index.php/IJDesign/article/view/459/161

Smits M (2001) Langdon winner: technology as a shadow constitution. In: Achterhuis H (ed) American philosophy of technology: the empirical turn, indiana series in the philosophy of technology. Indiana University Press, Bloomington, pp 147-170
Stapleton L, Dowd-Smyth CO (2003) Anaesthetising ourselves: engineering and technology education as a barrier to an ethical technology programme. In: Stapleton L, Kopacek P (eds) Proceedings of the SWIIS International Federation of Automation and Control Mini-Conference. Elsevier: North Holland

Steinert S (2016) Taking stock of extension theory of technology. Philos Technol 29:61-78. doi:10.1007/s13347-014-0186-3

Tripathi AK (2008) Technological transformation of human experience. ACM Ubiquity, vol 9, Issue 29 (July 22-28, 2008), pp 1-16. http://ubiquity.acm.org/article.cfm?id=1403926. Online Accessed 30 Jan 2017

Tripathi AK (2014) Philosophy of technology reflection. Int J Appl Res Inf Technol Comput (IJARITAC) 5(3):201-213. doi:10.5958/0975-8089.2014.00012.8

Tripathi AK (2015) Postphenomenological investigations of technological experience. AI Soc 30(2):199-205. doi:10.1007/ s00146-014-0575-2

Tripathi AK (2016a) Culture of sedimentation in the human-technology interaction. AI Society 31(2):233-242. doi:10.1007/ s00146-015-0581-z

Tripathi AK (2016b) Erratum to: culture of sedimentation in the human-technology interaction. AI Soc 31:243-244. doi:10.1007/ s00146-015-0584-9

Vardi MY (2017) Technology for the most effective use of mankind. Commun ACM 60(1):5

Verbeek PP (2001) Don Ihde: the technological lifeworld. In: Achterhuis $\mathrm{H}$ (ed) American philosophy of technology: the empirical turn, Indiana series in the philosophy of technology. Indiana University Press, Bloomington, pp 119-146

Verbeek PP (2005a) What things do: philosophical reflections on technology, agency, and design. Pennsylvania State University Press, University Park

Verbeek PP (2005b) Artifacts and attachment: a post-script philosophy of mediation. In: Harbers $\mathrm{H}$ (ed) Inside the politics of technology: agency and normativity in the co-production of technology and society. Amsterdam University Press, Amsterdam, pp 125-146

Verbeek, PP (2007) Beyond the human eye. Technological mediation and posthuman visions in mediated vision. In: Kockelkoren P (ed) Veenman Publishers and ArtEZ Press, Rotterdam. http:// doc.utwente.n1/54460/1/peter-paul_verbeek.pdf. Accessed 30 Jan 2017

Verbeek PP (2008) Morality in design: design ethics and the morality of technological artifacts. In: Vermaas PE, Kroes P, Light A, Moore SA (eds) Philosophy and design: from engineering to architecture. Springer, Dordrecht, pp 91-103

Verbeek PP (2011) Moralizing technology: understanding and designing the morality of things. University of Chicago Press, Chicago

Verbeek, PP (2015) COVER STORY: beyond interaction: a short introduction to mediation theory. Interactions 22(3):26-31. doi: $10.1145 / 2751314$

Vries MJD (2005) Technology and the nature of humans. In: Teaching about technology: an introduction to the philosophy of technology for non-philosophers. Springer, Dordrecht, pp 67-85

Winner L (1980) Do artifacts have politics? Daedalus. vol 109, no 1. The MIT Press, American Academy of Arts \& Sciences, pp 121-136

Winner L (1989) Techne \& Politeia. In: The whale and the reactor. A search for limits in an age of high technology. University of Chicago Press, Chicago, pp 40-58

Winner L (1990) Engineering ethics and political imagination. In: Durbin P (ed) Broad and narrow interpretations of philosophy of technology, philosophy and technology, vol 7, pp 53-64 